\title{
UNMAKING CONTACT: CHOREOGRAPHIC TOUCH AT THE INTERSECTIONS OF RACE, CASTE AND GENDER ${ }^{1}$
}

\section{Touch Tales $1^{2}$}

There is a moment that stands out as transformative and lies at the heart of many embodied intercultural tensions in my movement training during my undergraduate studies in the UK. It is the moment when, during my first contact improvisation workshop at the University of Plymouth in 1998, I was first touched by another body in the context of performance training. This touch, unlike the kinds of touch I had previously experienced during my classical dance training in India, was not instructional: it did not correct my posture, redirect my gaze or accentuate my mudra, for example. Instead this touch felt free, exploratory and consequently even threatening. This touch was of course mutual - by virtue of being touched, I too was touching my partner's body. But from where I moved, my reciprocating touch felt clinical, mechanistic, functional. While it allowed us to explore shifting points of physical contacts, so that we could be responsible for each other's balance and weight, it made me hyperconscious about how I moved. And yet, I could see from my tutor's demonstrations earlier, that the quality of movement it was intended to generate was supposed to be impulsive, instinctual and responsive. Far from it, my movements appeared as jagged, mechanical and planned as they felt. The touch was new, exhilarating, and terrifying, all at once. Not because I did not trust my partner's ability to support my weight. But because my Indian classicallytrained solo dancing body, that had hitherto danced within a clearly demarcated space of her own, and that was coded by culturally specific regulations that govern touch, had been placed in a situation that had led to a breakdown of these very codes. There was something about experiencing the language of CI colonizing my brown body in that white dominant space, without making any attempt to acknowledge or even consider the differences that 
constituted my embodiments, that highlighted the power differentials at play in the dance studio.

\section{INTRODUCTION}

In many ways that first encounter with contact improvisation has been the impetus of my lifelong, critical, and embodied enquiry into touch, contact, choreography, and asymmetries of power in contemporary dance practices, that has emerged slowly and steadily over two decades. This article puts forward the key theoretical and philosophical interventions I make in my in-progress book project titled Unmaking Contact: Choreographing South Asian Touch by foregrounding South Asian socio-politics, philosophies, and dance practices in discourse on choreography and contact. ${ }^{3}$

The article interrogates 'contact', understood by Global North contemporary dance discourse as choreography that is mobilized by shifting points of physical touch between two or more bodies, by attending to inherent, and often ignored, power asymmetries that are foundational to such choreographic practices. This 'unmaking of contact' is undertaken by deploying the lenses of race, caste and gender in order to argue for an intersectional, intercultural and interepistemic understanding of choreographic touch that may or may not involve tactility. It starts by examining CI and its now ubiquitous choreographic manifestation of partnering, as an aesthetic that works in colonising ways on South Asian dancers who train in primarily solo classical dance forms. This critique of the long-standing mythologizing of CI as a democratic movement language mobilizes intercultural and intersectional considerations through caste, gender and race politics to destabilize hitherto Global-North-centric discourses on the form. The article then moves on to place South Asian bodies, philosophies and discourses on touch and untouchability at the heart of its interrogation of choreographic touch. In doing so it 
expands understandings of 'contact' in dance-making through intercultural epistemologies, decentres notions of touch and contact which are often used interchangeably in Western dance discourse, reconceptualizes these notions through both Indian philosophies and the voices of four contemporary South Asian dance-artists, India-based Masoom Parmar, Diya Naidu and Anishaa Tavag and UK-based Akram Khan, and foregrounds the culturally specific politics and powers that govern their respective relationships to choreographic touch.

Masoom Parmar is a dancer, curator, and arts manager fueled by his training in bharatanatyam, kathak and odissi. As a man of Muslim-Zorastrian heritage he is invested in questions of identity and belonging, and his middle-class upbringing has inculcated in him a liberal world-view. Diya Naidu is an independent, feminist choreographer and dance-artist based in Bangalore and trained in Movement Arts and Mixed Media at the Attakkalari Centre for Movements Arts. Keen to explore how the rural, the global, the capitalist and the urban co-exist in Indian cities in bodily terms, Naidu is committed to making works that comment on these complexities of contemporary India. Anishaa Tavag is a South Indian dancer, editor, writer, and Alexander Technique teacher trainee based in Bangalore. She is invested in questions of collective responsibility and individual reflection in her writing and her choreographic practices. Tavag is conscious of her family's inter-generational upward social mobility through simultaneous caste privilege, and tries to reflexively consider her own social positions in everything she does. Akram Khan is a second generation Muslim, BritishBangladeshi dancer-choreographer based in London with a two-decade oeuvre of danceworks that come to life at the interstices of his diasporic identity positions, and his intercultural performance training in the north Indian classical form of kathak and Western contemporary dance practices. In this article I choose to foreground the voices of these four artists for very specific reasons. I remain in long-term scholarly-artistic dialogue with Khan. Following my first monograph on his oeuvre Akram Khan: Dancing New Interculturalism 
(2015), we have further deepened our critical reflections on contemporary dance and power asymmetries, and his thinking has shaped my project. Naidu's choreographed Rorschach Touch (2018), a dance experiment that meditates on touch, contact-making and social relations, is a case study in my book project, and Parmar and Tavag are performers in this piece. Their individual reflections on a shared performance project that speaks to my own book's enquiry so crucially felt important to foreground in this article. Most importantly, each of these artists' embodied relationship to social and choreographic touch and relational contact is distinct, and by foregrounding and not flattening out these differences, I hope to present a complex and unhomogenized picture of how touch is deployed in South Asian choreographies. Furthermore, in choosing to foreground their collective artist-voices alongside Indian critical thinkers and writers Sujatha Gidla, Uma Chakroborty, Ajantha Subramanian, Srinivasa Ramanujam, Sundar Sarukkai, Gopal Guru, Brahma Prakash and Aniket Jaaware, I am interested in tracing the divergences and points of overlaps between embodied realities and conceptual frameworks, and making space for the former in shaping and (re)framing dance discourses.

\section{NEW INTERCULTURALISM, INTERSECTIONALITY AND INTER-EPISTEMIC KNOWLEDGE-MAKING}

Methodologically this article starts where my first monograph left off, by making explicit the intersectional and the inter-epistemic interrogation of power and politics that, for me, lies at the heart of 'new interculturalism' (Mitra 2015). I want to continue to push for new interculturalism as a ground-up, minoritized-subject driven corporeality, aesthetic and embodied politics that decentres normative white Western ideologies, dramaturgies, and knowledge-systems - leading to the generation of new epistemes. In the last decade, alongside my own, several key and vital publications have positioned new modes of 
interculturalisms as minoritized subject-driven political and aesthetic movement in theatre and dance sectors in the Global North (Knowles 2010; McIver 2016; McIvor and King 2019; and Lei and McIver 2020). These collective voices have situated the central concerns of power and agency, re-claimed by minoritized artists from the ground up, as integral to the spirit of new interculturalisms, most strongly exemplified in the work on 'scalar interculturalism' by Justine Nakase (2019). In this article I wish to extend their lines of enquiries, by advocating for intersectionality and inter-epistemic knowledge-production as central to such interrogations and reclamations of power within the projects of new interculturalism. As per Kimberlé Crenshaw’s foundational conceptualization of intersectionality, racially minoritized brown South Asian dance artists are at the heart of my considerations of new interculturalism, as I analyse their experience of power and marginalisations vis-à-vis choreographic touch in the UK and in India, compounded further by discourses of caste and gender locations. By foregrounding and navigating through both the connectedness and the divergences as revealed in the words of transnationally situated South Asian dance-artists Naidu, Parmar, Tavag and Khan in interviews with myself between 2017 and 2020, I mobilize the theorizing of choreographic contact and touch in and through their embodied realities. Through their lived realities as dance-artists I am keen to locate, as per Boaventura de Sousa Santos's observation the interconnectedness and co-existence of Epistemologies of the South within the Global North, Epistemologies of the North within the Global South, and finally a firm grounding of Epistemologies of the South within the Global South itself (2018). In prioritizing the voices of these artists and their art as scholarship I also wish to "make visible, open up, and advance radically distinct perspectives and positionalities that displace Western rationality as the only framework and possibility of existence, analysis and thought" (Walsh 2018, 17). This approach echoes de Sousa Santos's proclamation, "we don't need another theory of revolution; we need rather to revolutionise theory" (2018, viii). 
My methodology to theorize through the voices and lived realities of dance artists alongside critical thinkers and writers from India and the Indian diaspora, responds to de Sousa Santos' call that Epistemologies of the South enables historically spoken for people to represent their experiences on their own terms, through mobilizing knowledge systems that do not even get considered as such by dominant epistemes (2018). This article then also speaks to new interculturalism as means for inter-epistemic knowledge making, as it theorizes touch and contact through intercultural scholarship, lived realities and philosophical considerations.

\section{Touch Tales 2}

I am sat in the concluding practical workshop to Mellon Dance Studies Seminar 2015 at Northwestern University, amongst a predominantly white group of participants. We have been instructed to embody the word 'decolonize' in whatever way we see fit. I choose to stand still, grounded, refusing to cave in the face of power, despite being questioned by some fellow white participants about how my choice of stillness could decolonize movement. I witness around me more than half the room default to the language of CI that looks like active motion, juxtaposed by my inactive choice to remain still. I encounter an interesting conundrum in this moment as I acknowledge within myself the disjuncture between the role of stillness in early CI explorations by Steve Paxton as captured for instance in his Small Dance, and the seeming move away from stillness towards perpetual motion by my fellow participants. White bodies and some bodies of color weaving in and out of weight sharing, liftings, balances and imbalances. I am wondering: how can CI decolonize anything? Has it in fact not colonized contemporary dance through its guise of liberation and democracy? As we sit in a circle to reflect on the workshop I gently throw open these question to the room. I share my reflections that I found it interesting that in response to the word 'decolonize' so 
many in the room turned to CI, and then I ask as a provocation 'have we in fact been colonized by CI?' The room falls silent. And then, gradually, there are reflections shared on CI's exclusionary politics as experienced particularly by racially minoritized people. As the conversation moves away from the discomfort I have generated, I am left wondering just how alienating CI is to Black and Global Majority and caste-oppressed peoples, especially in the context of decentering dance practices / studies vis-à-vis questions of power. I find myself thinking through the oppressiveness of touch within dance practices and the situations in which I am at the receiving ends of power and those in which power operates in my favour and thus, I am invisible to it.

\section{UNMAKING CONTACT (IMPROVISATION)}

Despite playing a key role in Global North contemporary choreographies and dance practices, touch, often referred to interchangeably as contact, remains under-examined within dance studies, but has received scholarly attention in other fields. Philosophy has contemplated the complex relationship between selfhood, the act of touching and being touched (Derrida 2005; Sarukkai 2009). Neuroscience has theorized touch as the most crucial of the senses with regards to its role in human development (Hertenstein and Weiss et al 2011). Psychology and somatics have championed the therapeutic value of touch-based therapies such as massages, and somatic practices like Alexander Technique, in the healthy growth of prematurely born babies, and for enhancing general well-being of people respectively (Field 2013; Fraleigh et al 2015). Sociology and cultural studies have identified touch as a vital medium of human communication, while also acknowledging it as a strictly regulated behaviour governed by culturally specific norms (Manning 2007; Guru 2009; Sarukkai 2009; and Classen et al 2005). Scholarship on the use of CI within movement therapy, as a mode of rehabilitation 
within community practices, also echoes its healing and generative properties (Houston 2009; Dymoke 2014). Yet, while its healing, generative and connective properties have been celebrated in dance studies, there is still an unmet need to identify and examine choreographic touch, especially as it shapes CI, as a discriminatory practice, through the intersectional lenses of race, caste and gender politics. This is a necessary corrective to the body of work on CI and contact-driven choreography in order to challenge 1960s/70s Global North dance attitudes that have equated its touching bodies with counter-culture liberation.

Steve Paxton, the practitioner to whom CI's emergence is attributed, reflects in a published interview with myself on how the form began as somatic explorations into how inter-bodily communications transpire through shared points of physical touch (Mitra 2018, 9). He notes that "[i]f you feel like you are being supported, say, under your rib, you can then use that as a fulcrum to test out the possibilities of movement that would not be possible if that point of contact or touch was removed. So suddenly, your whole body-surface becomes a possible connection to the earth. [...] Your partner is connected to the floor, you are connected to the floor, and you are mutually supporting and using the supports to discover and provide new movement possibilities" (Paxton in Mitra 2018, 9). Physical touch is thus central to and the driving force of CI through which contact of many kinds are initiated and maintained. Witnessing CI in practice has made me aware of how this touch appears to travel seamlessly between different points of bodily contact, regardless of the potential of social and bodily harm that might be generated by such intimacy. A key component of this appearance of seamlessness rests in the notion of 'improvisation' within the practice itself; the inherent idea that our responsiveness has to be instinctual and not intellectual, spontaneous and not premeditated. I strongly contend, based on my own experience, that being instructed and able to improvise spontaneously within CI signals its deeply privilege-wielding white foundations. In 
reality, therefore, not everyone can improvise freely without the fear of how power might enact on and harm our bodies in and through our CI partner's relational social-positionings. The hardest part of CI for me has always been to stop myself from pre-planning my next response - in order to try to control and pre-empt how and where I am comfortable being touched back. Simply put, it is the improvisational dimension of CI that really reveals the asymmetries of power that are foundational to the form - i.e., as participants we are never sure where and how we will be touched.

Keen to consider the intersectional ways in which CI carries the potential to harm its participants through upholding power-asymmetries in its founding principles and continuing practice, in our interview I question Paxton about the form's predominant whiteness:

RM : You mention that contact has been less successful in integrating black and brown people into its practice, and that it does remain a predominantly white movement practice. Would you have an answer as to why this is the case? (Mitra 2018, 13)

His response is significant:

SP: I've been thinking about this question for a very long time and yet I am not sure that I do have an answer. There have been a few of course. As the recent Black Lives Matter movement signals to us, what we once considered was institutionalized racism as practiced by the police is in fact systemic in our society, our culture. So, it might well be that rubbing skins with your oppressors is not an appealing prospect within contact. It seems to be a bit of a canary-in-acoal-mine situation, this. It warns us that something might be up, and has been, for the whole time that contact has been around (Paxton in Mitra 2018, 13). 
Paxton's reflections signals his whiteness as he articulates the realization that the democratic principles which he and his generation of CI practitioners felt were foundational to the practice do not in fact hold true vis-à-vis race and racially minoritized bodies participating in CI. In many ways Paxton's words consolidate ongoing lines of enquiry into the whiteness of CI as unpacked by Fred Holland and Ishmael Houston-Jones (1983), Danielle Goldman (2010, 2021), Ann Cooper Albright (2017), Hannah Yohalem (2018), Rebecca Chaleff (2018), and Keith Hennessy (2019) amongst others, all noting and problematizing the white and racist foundations and ongoing practice of CI to various degrees. Writing on touch and Black subjectivity in the African-American context Rizvana Bradley notes that "touch [...] evokes the vicious, desperate attempts of the white, the settler, to feign the ontic verity, stability, and immutability of an irreducibly racial subject-object (non) relation [...]" (2020). Bradley proposes that this creates "subjects whose conditions of existence sustain the fantasy of being-untouched" (2020). I find Bradley's postulations on touch as violent and harmful to Black subjectivity crucial here to delineate from white ways of thinking about touch, particularly in CI, as healing and generative. They further alert us to the need to being attentive to the ways in which whiteness exerts and maintains power in CI through touch. I observe in the conclusion to this published interview, that Paxton's honest and generous reflections necessitate an urgent consideration of the relationships between CI and broader politics of power.

Where this interview offers a valuable new perspective on this discourse is Paxton's observation that the form's whiteness points to a "canary-in-a-coalmine situation," [...] Paxton reflects on this in two ways: first, by acknowledging that claiming democracy between bodies that are historically in hierarchical relationships with each other with regards to continuing unequal power structures, may well make contact improvisation a form difficult for black 
and brown bodies to feel welcomed into [...]; second, Paxton suggests further that perhaps racial and cultural divides in our societies are too deeply engrained in a way that contact improvisation's democratic principles are not equipped to acknowledge or address. $(2018,16)$

Paxton's reckoning with the foundational whiteness of CI, signaled in his speculation that "something might be up, and has been, for the whole time that contact has been around" has led me to my own. Listening to him consider the potential of harm that can be inflicted by CI on racially minoritized bodies achieved in me two simultaneous realizations: the first, a much needed validation of my first ever experience of CI, where I was at the receiving end of whiteness's violence in the dance studio, that I have described in Touch Tale 1; and second, an admission that in some instances of participating in CI I must sure wield power against fellow participants in the room who are located in different social positions to my own. While my line of questions for Paxton came from my position as a racialized brown Indian woman at the receiving end of CI's raced power matrices in the UK, Paxton's response has alerted me to consider further how the intersections of power work within a CI session in say India or in the UK between brown-only South Asian bodies, where caste and not race becomes the lines through which power is exercised, invisibilized and experienced. My interview with Paxton has been a wake-up call for myself as a dance scholar to think beyond power and oppression in ways where they fundamentally intersect, most importantly in myself. Locating Paxton's words in the caste-apartheid context of India and the Indian diaspora, I must necessarily consider the implications of 'rubbing skins with your oppressors is not an appealing prospect within contact' (Paxton 2018, 13). And to understand physical contact and touch within the Indian caste-apartheid context which is built on the very premise of who one can (and cannot) touch, CI's critique has to be intersectional through the 
interconnectedness of race, caste and gender politics. As a savarna (caste-privileged) Indian dance scholar working on anti-racism in the Global North academy, this intersectional enquiry is crucial for me, so that I can expose the power that operates in my favour in certain dance contexts because of my caste-dominant position in India and the diaspora, while also critiquing how CI wields its whiteness against me in others. A discourse of choreographic touch and its implications on South Asian bodies therefore has to take into consideration the perniciousness manifestations of caste supremacy.

\section{Touch Tales 3}

It's March 2020 and I am reading an article by Sutapa Chaudhuri about the Indian poet laureate Rabindranath Tagore's dance-drama 'Chandalika'. In the piece Chaudhuri argues for Tagore's feminist and anti-casteist politics in his advocacy for female desire in Prakriti, a young 'untouchable' girl who falls in love with an upper-caste monk Ananda, in 1930s Bengal in India. She writes, "For Prakriti, the socio-culturally imposed selfhood is that of an untouchable, an outcast; her desire would only be ratified if it is expressed within her caste and class. To desire for the companionship, indeed, the love of a monk is like reaching for the stars for the untouchable girl" (2010, 53). Chaudhuri proposes that Prakriti's desire is in fact awakened by Ananda's radical vocalized request to Prakriti, 'jolo dao' (give me water), an act that is considered sacrilegious to both individuals concerned, "because in the Indian context, a holy man asking for water from an untouchable violates social as well and religious norm" (Chaudhuri 2010, 556). I am struck by the choreography of (implicated and denied) touch in Tagore's mobilization of the very words 'jolo dao'. I have never considered the words in this light before. I am struck particularly by how the words expose and work to undo the inherent asymmetries of power between caste-privileged Ananda and caste- 
oppressed Pakriti. These two words choreograph touch's ability to simultaneously dehumanize Prakriti's existence and Ananda's ability to validate it, at once. This reading then takes me back to a memory in India. I am fifteen and a dancer in a schoolteacher's choreographic tribute to Tagore's 'Poncho Naari' (Five Women). I am sat watching the rehearsal for 'Chandalika' where a senior student from school plays Prakriti. She is only a few years older than me and thinking back to that moment, I am pretty certain that the nuances of Tagore's feminist and anti-casteist protest-art are entirely lost, indeed concealed from us young and, I can't be certain I speak for all but very probably, predominantly casteprivileged dancers. I witness, and my senior from school participates in, unaware, of the devastating politics of untouchability unravel through Tagore's words. But neither our casteprivileged teacher nor the accompanying singers who articulate them, stop to explain the significance of touch in Tagore's choreographic lyrics. Much like the invisibility of white privilege, the collective caste and class privilege of all of us involved in our dance production remains invisible and goes unacknowledged at Lake Club, one of the centers of middle-class (and quite possibly caste-privileged) Calcutta that hosts us.

\section{REFRAMING CONTACT: CASTE POLITICS, TOUCH AND UNTOUCHABILITY}

Growing up in India, in a caste-privileged middle-class Bengali family with no awareness of how power operated in my family's favour, I was led to believe that caste was a discriminatory system of the past, that it had no place in our home or society, and that instead our social stratifications were informed by class. Ajantha Subramanian's words are a crucial reminder to anyone who shared my upbringing that "the history of caste [is] one of transformation, $[\ldots]$ this does not mean that caste has given way to some other form of social classification, such as class. While class is certainly an important form of stratification, 
continuities of class affiliation, stigmatization, and ascription within the most modern institutional and social spaces reveal the irreducibility of caste to economic differences." $(2019,13)$. Performance Studies scholar Brahma Prakash argues for the foundational nature of caste in India as permeating every fabric of society and its interactions:

Jati (caste) pervades nearly all spheres of Indian social, cultural, and political life. It is deeply rooted in social and cultural institutions in India. The caste system claims to have a divine origin and gets it sanctions from religious and philosophical texts; it has its commanding presence in rituals and customs. Beyond texts, caste is a living practice in Indian society with each caste having its own customs, practices and rituals. [...] Until recently, there was a belief that caste would gradually disappear with the vanishing of traditional social institutions. But the caste system has been reinventing its structure, even so, to fit into the cosmopolitan society. $(2019,19)$

Prakash clarifies that within the context of performance "the Indian caste system is about the politics of controlling bodies and spaces. Caste determines where one can perform and where one cannot. Performance in a way becomes enactment of power (often caste honour)" (2019, 20). This honour operates on the basis of a social hierarchy according to which the caste system classifies Indians into four varnas: at the top of the hierarchy are the Brahmins (the priests); next in line are the Kshatriyas (the warriors); then come the Vaishyas (the traders) and finally the Shudras (the laborers). There are those therefore who fall outside of this chaturvarna (four varna) classification, the Dalits.

Referring to the Brahmins as self-proclaimed classifiers of society, Tamil writer and theatre activist Srinivasa Ramanujam claims that "it is but natural that [the Brahmins] locate 
themselves at the apex of the social pyramid" $(2020,1)$ and create these hierarchized categories in order to maintain their own dominant status. This hierarchisation operates in and through "the human body [which] becomes the site where the ideals and anxieties of the category are made corporeal" (Ramanujam 2020,2). The relationship between the Brahmins (the classifiers) and the remaining three varnas (the classified) and the avarna (the unclassified), is reinforced by institutional power, and one of the most dehumanizing and defining features of this power manifests as classifying the avarnas, the Dalits, as the untouchables. As Ramanujam asserts, "[...] untouchability is not the by-product of the caste system. Untouchability is the essence.” (2020, 3). Sujatha Gidla describes the extent of this apartheid reality as a woman 'born an untouchable':

The untouchables, whose special role - whose hereditary duty - is to labor in the fields of others or to do other work that Hindu society considers filthy, are not allowed to live in the village at all. They must live outside the boundaries of the village proper. They are not allowed to enter temples. Not allowed to come near sources of drinking water used by other castes. Not allowed to eat sitting to a caste Hindu or to use the same utensils. There are thousands or other such restrictions and indignities that vary from place to place. $(2017,4)$

Uma Chakroborty in her book Gendering Caste Through a Feminist Lens notes the nature of this dehumanization processes, practices and principles as described by Gidla when she states that " $[\mathrm{m}]$ ost reprehensively, caste ideology denies subjectivity to the dalits by depriving them of dignity and personhood" (2003, 7).

In his article 'Phenomenology of Untouchability', philosopher Sundar Sarukkai examines the Indian philosophical foundations of touch and contact, in order to theorize the 
phenomenology of untouchability. Sarukkai's project also demonstrates how this practice impacts the psyche and interactions of all in contemporary Indian society at large. $\mathrm{He}$ reminds us that in some Indian philosophical traditions, touch or sparsha is the most important of human senses, perceived through only one sense organ, the skin. Contact or samyoga on the other hand is conceptualized as a relation experienced by two or more sense organs. Thus, while sparsha refers to the sensation of touch, perceived through the one sense organ of skin, samyoga implies a relation established through two or more sense organs, of which one could be the skin. Contact therefore can, but does not necessarily have to, involve touch, and touch can, in conjunction with one more sense organ, lead to contact, or a relation (Sarukkai 2009, 40). In this sense, touch is hence a sensation, while contact is a relation, and this distinction is key for my own critique of $\mathrm{CI}$ in intersectional and inter-epistemic terms.

Sarukkai further explains that while the relational capacity inherent in samyoga is experienced by the toucher and the touched, the sensation of touch itself is only inherent in the toucher. This distinction helps untangle the conflation of touch and contact as is so often evident in Western discourses on touch, exemplified in Erin Manning's thoughts on touch as a mechanism for "reaching toward" with its promise of generative possibilities of new relations $(2007,12)$. The practice of CI is also premised on this very conflation. A practice that is driven by the sensation of shifting points of touch, is termed and framed through its aim to generate contact, and hence relations, between participating bodies. In contrast, Sarukkai's signaling of a philosophical distinction between touch as a one-way sensation, and contact as a relation-generating act, of which touch may be one part, seems key to understanding the way touch operates in Indian social interactions, classical dance training and ultimately choreographic processes. Understanding touch in this way might help us to consider why South Asian bodies trained in solo classical dance forms, and consequently 
participating in CI, might find the conflation of touch and contact a difficult experience to navigate at an embodied level. While in Indian classical dance training, the sensation of touch is prevalent as a one-way experience, the experience of making relational contact is less so. Thus, embodying such a distinction between touch and contact, and entering the realm of CI, where they are considered one and the same, maybe a fundamentally disorientating experience for many South Asian bodies.

Sarukkai goes on to explain that within Indian philosophy, the skin consists of seven layers and that the visible layer of the skin is "only the seat of the cognitive sense organ corresponding to touch" $(2009,41)$. This visible layer's important function is also "intrinsically related to boundaries and surfaces" $(2009,41)$. In order to examine the complex relationship between the boundaries of skin to skin contact, as embodied in the practice of untouchability, Sarukkai draws on theologist Ariel Glucklich's scholarship on principles of dharma, the social principles of morality in Indian philosophy, to argue for the skin as inscribed by boundaries of dharma. The skin therefore becomes the very mechanism through which boundaries are expected to be maintained. Sarukkai thus brings us to understanding touch as a 'moral sense' before demonstrating how this manifests in the socio-cultural practice of untouchability $(2009,42)$. He breaks down the word 'untouchable' into its constituent parts: UN-TOUCH-ABLE. He argues that depending on where one places the emphasis of ability or lack there of, two different readings of the word are produced. The first possibility is NON-TOUCH-ABLE, where the inability to be touched is placed on the object, such as say air. The second and more troubling possibility is TOUCH-UNABLE - where a subject is unable to fulfil the act of touching:

There are important consequences for the person who does not fulfil this potential of touching. The model of touching others is that of touching oneself. Thus, in the 
most primal sense of the term, denying oneself the fulfilment of touch leads to denying oneself the capacity to touch oneself. [...]. The person who refuses to touch an untouchable suffers from touch-un-ability. (Sarukkai 2009, 43)

In the context of the social practice of untouchability, Sarukkai argues that it is indeed Brahmins who suffer from touch-un-ability by denying themselves the ability to touch Dalits. But he also furthers his position by adding that "the untouchability experience conditions us to be more cautious towards touching in general. So, the act of touching becomes problematical, because every act of touching becomes reflective $[\ldots]$ becomes a judgement" $(2009,44)$. This leads us to a place of distrust with making contact via touch, per se: The organ of touch is the skin. And if you do not like to touch something then you have to 'close your skin'. But closing the skin is to close the first means of contact with the world [...] simply put, the moment you close the skin you die. $(2009,44)$

This closing of skin becomes apparent in the deeply embedded culturally specific and globally circulated gesture of the Indian greeting of the namaskar, the folding of two hands in a prayer position. As Gopal Guru speculates in his article 'Archeology of Touch', the gesture was potentially designed to be as much a mechanism for ensuring hygiene by avoiding physical contact with a stranger, as it was to not have to touch the stranger without knowing their caste, to "serve the purpose of avoiding the touch of others, perhaps the repulsive other - namely, the untouchables" $(2017,213)$. To think of this deeply embodied gesture as a mechanism of caste apartheid is a necessary unsettling realization to me as a savarna woman. 
In his profound intervention Practising Caste: On Touching and Not Touching Dalit Studies scholar Aniket Jaaware notes that Sarukkai's and Guru's essays "seem to take touchability/untouchability as already constituted facts and / or practices" without "explor[ing] how these are constituted, in the phenomenological sense" $(2019,7)$. In Jaaware's book "caste is removed from the domain of subcontinental specificity and associated with the simple divide between touching and not touching, of bringing near or keeping something or someone at a distance" (Rao in Jaaware 2019, VIII) through an interrogation of the social and philosophical orders that create it and lend it sustained credibility. Jaaware cuts to the chase when he claims that as "a matter of practice, caste is determined by birth, rather than by practice" $(2019,66)$ emphatically reminding us of the "tight and uncompromising fit between caste and birth, between caste and being [that] cannot be undone, or even disturbed" $(2019,67)$. Highlighting the obsessive interdependency between caste and touch he astutely asks "why there are regulations on touch when it is precisely caste that precludes the possibility of touch?" $(2019,72)$. He argues eloquently through this conundrum for the fragility of the Brahmin body's superiority identifying the purifying nature of these regulations as the codes that "mark the vulnerability of the Brahmanical body [...] vulnerable to touch by almost everybody except the Brahman himself, provided he is not in an impure state" $(2019,95)$. The paradox of this, he reveals, is that "the one substance that cannot ever be contaminated is [...] the dalit body" as it "does not have the power to be contaminated" while "in contract [...] with increasing graduations, the non-dalit bodies have the power to be contaminated and thus must fear the contact with dalit bodies" $(2019,99)$.

Thinking through the implications of touch, untouchability, contamination, regulations and power as both exercised by and imposed upon Indian dancing bodies requires then a further 
fundamental unsettling of CI as touch-reliant form that invisibles the power asymmetries that operates between them at the intersections of race and caste politics, instead of romanticizing the form as committed to politics of liberation.

\section{MY TOUCH UN-ABLED UPBRINGING}

I am interested in the conjunctions between Sarukkai's concept of 'closing our skin' as a Brahminically inscribed thinking and practice that keeps different stratifications of social categories in place, and Jaaware's observation of the 'vulnerability of the Brahmanical body' as foundational to keeping their own power in place. It makes me reflect on my own casteprivileged and middle-class Bengali upbringing in 1980s and 90s Calcutta through my 'closed skin'. My mother tells me that my family consciously denounced caste affiliations. I did not know my caste lineage until I started probing while researching for this project. I am told that my father belongs to the Kayastha caste and married my mother despite much resistance from his family because my mother's family were affiliated to the Brahmo Samaj, a reformed Hindu sect who, amongst many other things, claimed to have denounced the caste system. This made it impossible for my father's family to identify my mother's caste, which I am now told is a mixed lineage of Kayastha and Brahmin. My lineage is thus very clearly a savarna-one, and I undoubtedly grew up invisible to my own caste privilege, just as my parents continue to remain invisible to their own. In retrospect though it becomes abundantly clear that many complex rituals of touch-un-ability and closed-skin-ness fundamentally shaped my upbringing and interactions with people, dependent upon their caste, class and social motilities, both at home and beyond. 
Washing our hands and feet to get rid of dirt after coming home from the outside was not only a hygienic ritual, but regularly punctuated by statements like 'you never know what or whom you've touched'. In the hottest of climates where roaming around barefoot was always the desired option, we had to wear sandals at home so our feet didn't touch dirty floors. In contrast however my nanny and our domestic workers were expected to remain barefoot inside the home, did not join us for meals at our dinner tables, drank and ate from cups, glasses and plates, and used toilets that were distinct from ours. It is also in the public sphere of 1990s Calcutta, as a young woman taking public transport to and from school, that I discovered how in these crowded environments, people from potentially all genders, caste and class intersected and stood closely compressed against each other. But as Jaaware explains of such 'occasions of touch' within Indian public life, I did not actually experience touch as a two-way sensation and experience:

Think of the crowded city bus, or tram, or, in Mumbai, the local train, There are great many human beings standing or sitting beside each other, touching each other with various body parts (almost never with fingertips). This is a remarkable picture, since we believe that very few of these human beings experience touch even though they are all physically compressed by each other. It is possible to suggest that the sense of touch is neutralized for the duration of the journey. The experience must be different in different urban and metropolitan centres, depending on what is thought of as touch and what is not, and what are the specific regulations governing touch. In Mumbai, even if whole lengths of bodies are touching each other from all sides, there is no experience of touch (unless of course there is some kind of sexuality involved. $(2019,80)$. 
In his last sentence Jaaware signals the moment when in these instances of not experiencing touch turned to unwanted, disturbing violation of people's close proximity through sexual touch. On another end of the spectrum however, I grew up watching television images of thousands of people throng to touch the feet or hands of spiritual leaders and receive their blessings, as physical contact with them was believed to have a sacred power to heal.

In the codified aesthetic sphere of my classical kathak training under three different female Hindu gurus, codifications around touch persisted. In each of these tutelages, we were encouraged to touch the feet of our gurus to receive their blessings before and after each class. There were also occasional moments when my gurus would use instructional touch with their hands to correct our mudras or our positions. In a published interview with myself, Akram Khan reveals how in his first dance piece Loose in Flight in 1999, the repetitive motif of repositioning his elbow to kathak's first position, is an echo of his own muscle memory of this very instructional and corrective nature of touch from his teacher Kumudini Lakhia (Khan in Mitra 2017). My experience of kathak remained inscribed as per Sarukkai's postulations of touch as 'one-way sensations', without the materialization of any relational contact. As a result, I have come to look upon kathak as a predominantly solo dance form, where the dancer's personal space is clearly demarcated through extended arms, and no other body invades this space. Even as I learnt to narrate stories of love, eroticism and intimacy, we were taught to mime these moments of relational interactions, evoked through abhinaya, strictly codified gestures.

In all these instances, Sarukkai's distinction between sparsha (touch) and samyoga (contact), prevailed. Governed closely by such codified and hierarchical sensibilities around touch and an innate distrust of contact-driven relations, I moved to the UK at the age of eighteen to 
pursue a degree programme in Theatre \& Performance. Here I encountered CI for the first time as described in Touch Tales 1 , and this was an undeniably destabilizing and disorientating experience. Thinking back to that disorientation as a result of my closed-skinness in the studio, two simultaneous power structures were operating in and upon my body: my caste privilege was confronting the racial privilege of my white lecturer and my peers. This realization borne of the need to work through these two competing structures of power and privilege, one I was invisible to and the other that I was subjected to, drives the final part of my article.

\section{UNMAKING CONTACT}

Understanding the reciprocities between social and philosophical conceptualizations and practices of touch in South Asian and South Asian diasporic cultural contexts, as described above, and their choreographic manifestations in contemporary South Asian dance practices is key to study of 'unmaking contact'. In other words, South Asian embodiments of sociocultural codes of touch and non-touch are deeply embedded within us as social beings and, by extension, as dance artists. The specific ways in which (non) touch manifests in South Asian choreographic practices is thus vital to consider, as I consolidate my argument for 'unmaking contact' through embodied modalities which both speak to and cut up against the philosophical considerations already laid out in the previous section. I consider these convergences and divergences key to argue for an inter-epistemic understanding of choreographic touch.

In this section, then, I expand the unmaking of contact through a comparative analyses that cuts across race, caste and gender politics, weaving in and out of interview excerpts between four South Asian dance artists: Diya Naidu, Masoom Parmar and Anishaa Tavag based in 
India and Akram Khan based in the UK who I interviewed individually between 2017 and 2020. Over the course of the three years, I posed the same questions to these four danceartists: do you think touch and contact mean the same thing? How has your upbringing impacted your understanding of touch and contact? Within your dance and performance training, how have you experienced touch and / or contact? As I navigate their words, it becomes clear to me, and it is imperative to set out at the start of this section, that their responses rarely overlap with each other and also with the theoretical positions on touch and contact already examined in detail in this article by Sarukkai and Jaaware. Their distinct and divergent perspectives demonstrate to me the vitality of integrating their voices and lived experiences into my project of reframing choreographic touch in inter-epistemic dimensions, alongside and in conversation with the voices of the Indian critical thinkers I have already foregrounded.

For all four of the artists, it is clear that the concepts and experiences of touch and contact are distinct, and not to be conflated. But their views rarely coincide. For Tavag "touch is a little bit more immediate and fleeting, and contact connotes something more sustained and more shared" (2020). Tavag makes a distinction between touch and 'in touch' suggesting that the latter is perhaps not so different from contact. Khan's thinking expands on Tavag's understanding of contact as a more complex system of communication :

Touch transpires as a physical action and reaction between two bodies that meet each other at two or more given points. Contact, on the other hand, goes beyond that. For example, I could make contact with someone just by looking at them, or them looking at me. Contact doesn't have to arise from touch alone. [...] contact is more a complex form of communication between people. In that sense, touch is 
a simpler mode of communication to understand and react to. (in Mitra 2017, 388)

While Tavag and Khan's understandings of these two words align with Sarukkai's distinction between sparsha (touch) as a one-way sensation and samyoga (contact), a reciprocated relation, for Naidu however it is touch that is the more complex and nuanced of the two concepts as she feels that it is "possible to touch even deeper with the eyes than the skin sometimes" (2019). And it seems this is the case for Parmar too as he offers this beautiful meditation on the two words:

Just to put it in one sentence, according to me, "all contact is touch, but all touch is not contact". I could touch you with my eyes, and that is also what we feel ... you would have felt it as a woman; you know when a man is looking at you. And as an effeminate gay man, I feel it too - being touched by people's looks. So no, I don't think they are one and the same thing. Even to look at it through the prism of classical dance, especially in Bharatanatyam, we don't touch our partners. If you have to embrace somebody, you embrace the air around them. [...] So there is no physical contact, but you are touching them and this is implied. I definitely think they are two different things. I feel touch is more visceral. Thinking of travelling on the Bombay local train - you are all in close contact. But is this touch? Probably not, because your body gets so used to it. So I guess for me touch has a deeper meaning. (2020)

Parmar's reflections on the Bombay local train, and how passengers' bodies are desensitized to the close and compressed proximity to each other, making this a habituated and clinical embodiment of physical contact that is not meaningful for most concerned aligns with 
Jaaware's reflections on the same instance that I discuss in the previous section. Both signal that such physical contact is clinical and mechanical and does not offer the richness of reciprocity and meaning offered by touch. These differing understandings on touch and contact suggest that these considerations are deeply subjective and relational to our own social positionings, and any attempt to theorize them has to consider the landscape and complexity of this discourse as fundamentally pluralistic and divergent, placing embodied realities and understandings of these contacts at the center of these considerations. And what constitutes these subjective understandings of touch and contact are embedded in our upbringings and for dance-artists, reinforced in our training classrooms in both classical and contemporary contexts.

Khan reflects on the familial messages he grew up with on touch and contact, in his BritishAsian and Muslim upbringing in 1980s London:

I grew up with the implicit understanding that touch was forbidden, especially between the opposite sexes. Although between family members it was permitted. But there was also a fine line between how your parents touch you, and up to what age this was still considered permissible. All those conditions were very finely and socially tuned. But it was very clear that touching between the two sexes was forbidden. When I say forbidden, I must emphasise that this sense of the forbidden was reinforced implicitly, without anybody ever saying so in explicit terms. I grew up in an environment where I was exposed to messages, subconscious messages, around touch. Like, for example, through Bollywood films. In that context, the touch of a hand was a huge thing. That was like sex, full on sex. (in Mitra 2017, 389) 
For all four of the dance-artists, within the context of the classical dance training world, touch was experienced as a corrective gesture. Tavag recalls that during her childhood bharatanatyam classes she was "afraid of being hit by the little stick' and remembers 'seeing some students being hit on the knuckles with it" (2020). Her memory of this stick, the tattakali, was that "it kept time and also kept us in check" (2020). Parmar too remembers the disciplinarian tattakali but his memory provides an insight into its gendered use in his bharatanatyam classroom in a small town in Gujarat with a female teacher. He says that while his teacher would correct the postures or gestures of the female students in the class, by touching them with her hands, "she would walk up to me but the touch would be with the tattakali" regardless of what part of his body was being corrected (2020). He reflects that growing up in a liberal and physically demonstrative home, this experience in the classroom was eye-opening and disorientating but taught him that not everyone experienced or understood physical contact in the same way as himself. Naidu too does not "remember any form of touching in the bharatnatyam or kathak classes except maybe to correct a posture or gesture by shifting or aligning it a little differently" (2019). In addition to experiencing touch as a corrective experience in his kathak training as already mentioned in the previous section, Khan says he "experienced touch while learning to dance narrative components of Hindu myths of, say, Krishna and Radha" $(2017,390)$ and was made to understood that in this context touch was permissible as it was framed as sacred. Parmar astutely questions the inherent hierarchisation and potential exclusion of bodies within classical dance spaces through precisely this pervasive idea of the sacred:

What I have always thought, and maybe I am wrong, but this is my interpretation, that dance always talks of the lover - but one of them is divine, and the other is human. So even if it's the divine embracing the human or the other way round there is a hierarchy? Right? And embedded in this hierarchy there is touchability 
and untouchability. The supposed divinity of the form - that lends itself to keeping such hierarchy in place. (2020)

Parmar's reflections are vital here as Brahminical supremacy is woven into the fabric of the Natyashastra, the foundational text for Indian classical dance forms, as recently argued by Anurima Banerji (2021) and its inherent casteist histories of erasures and appropriations are also foundational to the formational histories and practices of Indian classical dance forms, especially bharatanatyam, as explicated by Nirthya Pillai (2021), Davesh Soneji (2012) and Hari Krishnan (2019) amongst others. In a conversation with Sundar Sarukkai over a Skype call on 20 September 2019, we speculated whether the habituated lack of physical contact between dancing bodies in these classical forms, even their primarily solo-ness themselves, may well have been driven by such exclusionary politics of touch and untouchability. And although there are distinctions between how these manifest in the different classical forms, they continue to remain pervasive across them.

When we move on from the classical dance world to the world of contemporary dance training, for Naidu and Khan, gender and race intersect in the studio space to shape their understanding of touch and contact. Naidu recalls that teachers and modes of pedagogy "in these space are more tactile in the way they transfer information or give feedback and there is a general sense of liberated, non-gendered and able-bodied safety one experiences" (2019). But she also reflects on the seemingly gendered nature of these interactions within the classroom, and how these impacts their behaviours and beings beyond it:

I do remember teachers having to really talk through and hand-hold some students into being comfortable with touch with the opposite sex. An experience I remember very clearly is how our bodies changed during those first months of 
contact improvisation classes. We were all walking around with this sense of openness, freedom and awareness, revelling in the momentary freedom from gender. And then, when class finished, we would go outside onto the street in large groups as dance students do. Day after day, I would watch as the girls, me included, systematically and sadly closed our bodies again. The walk home would prove very unpleasant if we continued to have that sway and exuberance, indeed that inviting quality. The boys on the other hand, barely seemed to notice they had left the studio. This is something I still feel poignantly till today and it influences much of my research and work. (2019)

The theme of discomfort, although not necessarily gendered in this instance but instead racialized, is echoed in Khan's memory of his first contact improvisation class at De Montfort University in Leicester, UK, where he enrolled onto their undergraduate dance programme:

It was terrifying. But to be honest, even before I encountered my discomfort with touch in the studio, there was a whole other issue I had to confront. Before touch . . . before touching somebody else, I had to get to grips with the idea of touching myself, but in a non-sacred context. Because in Islam, we are constantly touching ourselves; we wash our face five times a day to cleanse our bodies. But this emphasis on self-touch is that it is once again framed as sacred, between oneself and God. In addition to confronting these complex emotions around touch and touching, I had to confront the issues I had with the medium of such touch itself my own body, and how I perceived it from within. In a contemporary dance environment, where most women and men were absolutely fine with revealing 
their bodies in very open ways, I concealed myself more and more. And I did this quite literally by putting more and more layers of clothes onto me. So I would wear a t-shirt, on top of another t-shirt, on top of another t-shirt, and then a cardigan, and a hat, and trousers and a hoodie. And to be honest, I've never been able to shake off this vulnerability of revealing myself, fully. This sense of selfconcealment continues to shape my work. This is why I cannot perform naked, because of the fear of revealing my body. During my movement training this feeling was heightened because most of the bodies of my peers around me fitted the mould of what a Western dancing body is expected to look like. But my body did not fit this image at all. So, for me it was frightening ... terrifying. And then, on top of that, there was touch. (in Mitra 2017, 391)

When I asked if his tutors at university ever made space to discuss the different cultural codes bodies of color bring into the studio space in negotiating contact, he said: No, not once. But I want to clarify that this does not necessarily mean that the teachers were not aware of the issues. My teachers might well have been aware and felt that they were helping me deal with my awkwardness by guiding me through it? But nobody questioned... nobody directly asked me 'are you feeling uncomfortable?' But the thing is, the body doesn't lie, so of course they saw I was uncomfortable in my body. (in Mitra 2017, 391)

Naidu observations about the tendency of white teachers of CI workshops within Indian settings is equally troubling: 
I think the sensitivity of a teacher to the exact individuals in the room is of paramount importance. I have seen many European teachers talk rather patronizingly to Indian students, assuming they never touch the opposite sex, and now they will be liberated from their social conditioning via this class. [...] I think what annoys me most is when the teacher, usually from a first world country, assumes that this is somehow a superior way to be, interact, touch or think about other bodies and to then witness very naive, unsuspecting and awestruck young dancers lap up that discourse because they are so smitten with the skill. There is barely any real time spent on talking about how or why this way of moving with other bodies in space came about and what it meant socially or culturally at the time. (2019)

Both Khan and Naidu, implicitly and explicitly, signal the condition of Sarukkai's concept of the 'closing of skin' through their distinct South Asian upbringings, when reflecting on their training in CI. For Khan, the potentiality in making contact as per Sarukkai's understandings of samyoga, that is to enter into a relation with another body, is where the place of discomfort opens up, as his skin, his moral sense, mobilizes boundary-maintenance. For Naidu, the potentiality in making contact with other bodies within a studio environment comes somehow supported and sanctioned by accepting the norms of Western pedagogies. These knowledge systems momentarily disorient, destabilize and undermine her own innate ways of knowing that are inscribed into her skin, her moral sense, but she is able to navigate them within the studio. But as she leaves the studio walls and walks onto the streets, her skin or her body closes up again to keep moral boundaries in place. Despite their very distinct South Asian upbringings and lived realities in India and the diaspora respectively, Naidu and Khan seem to be bound by an embodied moral sense. Their experiences with the whiteness of contact are 
further complicated and nuanced by their own respective embodiment of gendered brownesses. While it is true that Khan would have encountered the whiteness of CI more explicitly during his dance training in the UK as the only student of color, Naidu's experience of the form's whiteness is perhaps more implicit in a class of other Indian students, but being taught and led by a white CI teacher. But for both of them, what is undeniable is the experience of destabilization in having to navigate the whiteness of the form in their brown skins.

I notice that while power asymmetries related to race and gender are spoken about with ease, questions of caste politics are not explicitly and sustainedly present in my conversations with the four artists. The closest we come is to Parmar's reflections on the hierarchies in classical dance because of the love expressed in narratives between human and divine characters. And Tavag mentions that although she isn't fully certain, she wonders whether CI spaces in India may well operate in exclusionary ways because of India's inherent and internalized practice of discrimination via colorism, excluding participants with darker skin from the practice.

Colorism and casteism are closely related discriminatory realities and practices in India and the Indian diaspora. The absence of caste politics from my conversations with the four artists signals a caste-blind phenomenon akin to the color-blind rhetoric of whiteness. To move to a place of caste justice, or race justice, or both, vis-a-vis choreographic touch, requires a deep reckoning with how power operates in these practices, and a recognition of how power asymmetries are perpetuated and kept in precisely through such invisibilization of power. It requires a reckoning with our role as artists and scholars in these invisibilizations. My conversations with these artists opened up generative spaces for such reckonings.

\section{Conclusions}


Punctuated and framed by three personal and reflective 'Touch Tales', this article has offered a critique of $\mathrm{CI}$ and its deemed democratizing principles as a movement practice, by focusing on intersectional considerations of race, caste and gender. It has then expanded prevalent discourse on 'contact' by foregrounding South Asian philosophies and practices of social and choreographic touch. Navigating the edges and centers between the conceptualizations of Sarukkai and Jaaware and the embodied realities of Naidu, Parmar, Tavag and Khan on touch and contact makes explicit the urgent need for Global North dominant dance studies to reconsider choreographic touch in intercultural, inter-epistemic and intersectional ways that they currently do not foreground. This is vital not only to expand the discourse of choreographic touch beyond these existent and limiting frameworks, but as an urgent reminder that far from being a practice of liberation, $\mathrm{CI}$ can be a violent practice in its inherent invisibilisation of the different power asymmetries that it harbors and perpetuates, in the guise of democracy. The matrix of lives realities and conceptual frameworks holistically explored in this article also reveals just how subjective these embodied understandings of touch and contact are for these South Asian dance-artists, and how driven these understandings are by their positionalities in their respective social and dance-worlds. In this, the article merely manages to make a gentle dent into the substantial gap within our field with regards to the study of choreographic touch.

By foregrounding intersectionality and theorizing with and through the embodiments of four South Asian dance artists alongside thinkers and theorists in its interrogation of power asymmetries in Global north practices and discourse of choreographic touch, the article has demonstrated that new interculturalism is an embodied, artistic, political and scholarly methodology that has the potential to generate new knowledge-systems at inter-epistemic dimensions. These new knowledge-systems are embodied in artistic practices and sit 
alongside, and more importantly, test and challenge the theoretical and scholarly positions of Sarukkai and Jaaware. In this the article has borne out Boaventura de Sousa Santos's location of Epistemologies of the South within the Global North (in Khan), Epistemologies of the North within the Global South (Naidu), and Epistemologies of the South within the Global South itself (Naidu, Parmar and Tavag). The article also points to the need for new interculturalism scholars to interrogate power asymmetries across intersectional matrices, and necessarily implicating ourselves (with)in them. Throughout this article, the 'touch tales', the three seemingly disparate but fundamentally linked interludes from my own embodied reality as a caste-privileged, anti-racist Indian dance-scholar in the UK diaspora, calls urgent attention to the myriad ways in which touch in choreographic practices, across temporal and transcultural contexts, embodies, rests on, perpetuates and exposes power asymmetries in our social and art worlds. They are crucial mechanisms for the ways in which I argue new interculturalism as a methodology must be mobilized to ensure self-reflexivity. They are reminders that as a scholar I need to take ownership of when and how I wield power, and when and how power is wielded over me. They are reminders of my own experiences and reflections that ground this study, navigating between the personal, the political, the philosophical, and the artistic dimensions of this article. They illustrate the need to intellectualize, reconceptualize, critique, and advocate for choreographic touch's power to heal, humanize, communicate, forgive, comfort, soothe, and enable, while it can also violate, dehumanize, repulse, offend, frighten, forbid, distance, locate and fix peoples and embodiments. They have, I hope, offered anchoring opportunities through this piece to bring the discussion back to the lived condition as one that operates between intersecting power matrices, wielding power in some while being wielded by power in other instances. 
I wish to acknowledge here that my interview with Paxton was key in enabling me to reconsider what mattered most in my enquiries on choreographic touch: and that is to centralize the different kinds of intersecting power asymmetries that operate within choreographic practices that rely heavily on touch, in order to foreground race, caste and gender within the discourse. As I observe in the conclusion to my Paxton interview: "[b]y starting from a place where focus is placed on the colonial force of contact between bodies who are moving through unequal power structures" an intersectional and inter-epistemic shift in the discourse and a fundamental reimagining of choreographic touch "is made possible, if not necessary, to critique the longstanding mythologizing of contact improvisation as a liberating and democratic language of movement exploration" (Mitra 2018; 17). This undoing of the universalizing principles of CI has thus opened up ways to see why unmaking contact as a project becomes vital.

To unmake contact then is to consider who and what is at stake for those who are forced to make contact and enter into relations that they have been oppressed by. To unmake contact is to remember that touch and contact are not the same acts or experiences. To unmake contact is to question the hierarchies of power that not only haunt oppressed peoples who are expected to engage in the acts of touch and touching in dance-works, but also inform the sensibilities of those who read and judge them. To unmake contact is to determine the mechanisms and tools with which to reimagine choreographic touch, beyond the constraints of contact improvisation and partnering, as Global North dominant discourses dictate. To unmake contact then is to ultimately remake contact on our own terms.

\section{Acknowledgements:}


I wish to express my gratitude to all the dance artists who contributed to my lines of enquiry with important insights and experiences: Akram Khan, Diya Naidu, Masoom Parmar, Steve Paxton, and Anishaa Tavag - your words are foundational to this article and my thinking. I also wish to thank Sundar Sarukkai for engaging generously with an earlier version of this article and encouraging my project. I further wish to thank my anonymous peer reviewers for their invaluable and critical offerings that have strengthened this article and my longer-term thinking for this monograph project. Finally, I wish to acknowledge that the title of this piece 'Unmaking Contact' came into being in conversation with my colleague and friend Broderick Chow who suggested it, pointing out that it would be an implicit nod to the dismantling of dominant discourses in cultural anthropology that mobilize 'making contact' to often describe the first point of encounter between colonial forces and indigenous groups, between the Global North ethnographer and their Global South subjects of enquiry. His suggested title gets to the heart of this project and for this I am deeply grateful.

\section{Works Cited:}

Albright, Ann Cooper. 2017. "The Politics of Perception." In The Oxford Handbook of Dance and Politics, edited by Kowal, Rebekah J., Siegmund, Gerald, and Martin, Randy, 223-243. New York: Oxford University Press.

Banerji, Anurima. 2021. "The Laws of Movement: The Natyashastra as Archive for Indian Classical Dance." Contemporary Theatre Review 31 (1-2): 132-152.

Bradley, Rizvana. 2020. "The Vicissitudes of Touch: Annotations on the Haptic." Boundary 2: An Online Journal. < https://www.boundary2.org/2020/11/rizvana-bradley-thevicissitudes-of-touch-annotations-on-the-haptic/>. Accessed on 30 November 2020. Chakroborty, Uma. 2003. Gendering Caste Through a Feminist Lens. Calcutta: Stree. 
Chalef, Rebecca. 2018. “Activating Whiteness: Racializing the Ordinary in US American Postmodern Dance.” Dance Research Journal 50(3): 71-84.

Chaudhuri, Sutapa. 2010. "Signifying the Self: Intersections of Class, Caste, and Gender in Rabindranath Tagore's Dance Drama Chandalika (1938).” Rupkatha: Journal on Interdisciplinary Studies in Humanities 2(4): 549-556.

Classen, Constance, ed. 2005. The Book of Touch. Oxford: Berg.

Derrida, Jacques. 200. On Touching - Jean-Luc Nancy. Stanford: Stanford University Press. Dymoke, Katy. 2014. "Contact Improvisation, the Non-Eroticised Touch in an "Art-Sport"." Journal of Dance and Somatic Practices 6(2): 205-218.

Field, Tiffany. 2014. Touch. Boston: MIT Press.

Fraleigh, Sondra, ed. 2015. Moving Consciously: Somatic Transformations through Dance, Yoga and Touch. Chicago: University of Illinois Press.

Gidla, Sujatha. 2017. Ants Among Elephants: An Untouchable Family and the Making of Modern India. New York: Farrar, Strayd and Giroux

Goldman, Danielle. 2010. I Want to Be Ready: Improvised Dance as a Practice of Freedom. Ann Arbor: University of Michigan Press.

Goldman, Danielle. 2021. “A Radically Unfinished Dance: Contact Improvisation in a Time of Social Distance." TDR: The Drama Review 65 (1). 62-78.

Guru, Gopal. 2017. “Archaeology of Untouchability”, The Cracked Mirror by Gopal Guru and Sundar Sarukkai. New Delhi: Oxford University Press.

Hennessy, Keith. .2019. "Questioning Contact Improvisation.” <https://dancersgroup.org/2019/10/questioning-contact-improvisation/ >. Accessed on 1 April 2019. 
Hertenstein, Matthew J, and Sandra J. Weiss, eds. 2011. The Handbook of Touch:

Neuroscience, Behavioural, and Health Perspectives. New York: Springer Publishing Company

Houston, Sara. 2009. "The Touch Taboo and the Art of Contact: An Exploration of Contact Improvisation for Prisoners." Research in Dance Education 10(2): 97-113.

Jaaware, Aniket. 2019. Practicising Caste: On Touching and Not Touching. New York: Fordham University Press

Krishnan, Hari. 2019. Celluloid Classicism: Early Tamil Cinema and the Making of Modern Bharatanatyam. Middletown: Wesleyan University Press.

Manning, Erin. 2007. Politics of Touch: Sense, Movement, Sovereignty. Minneapolis: University of Minnesota Press

Knowles, Ric. 2010. Theatre and Interculturalism. Basingstoke: Palgrave Macmillan Lei, Daphne P, and Charlotte McIver, eds. 2020. The Methuen Drama Handbook of Performance and Interculturalism., Bloomsbury Methuen.

McIver, Charlotte. 2016. Migration and Performance in Contemporary Ireland: Towards a New Interculturalis., Basingstoke: Palgrave Macmillan

McIver, Charlotte, and Jason King, eds. 2019. Interculturalism and Performance Now: New Directions?, Basingstoke: Palgrave Macmillan

Mitra, Royona. 2018. "Talking Politics of Contact Improvisation with Steve Paxton.” Dance Research Journal 50(3): 6-18.

Mitra, Royona. 2017.“Akram Khan on the Politics of Choreographing Touch.” In Contemporary Choreography: A Critical Reader, edited by Jo Butterworth, and Liesbeth Wildschut, 385-397. $2^{\text {nd }}$ ed. London: Routledge.

Mitra, Royona. 2015. Akram Khan: Dancing New Interculturalism. Basingstoke: Palgrave Macmillan Ltd. 
Naidu, Diya. 2019. Interviewed by the author via email. February 26.

Parmar, Masoom. 2020. Interviewed by the author via Zoom. 9 September.

Pillai, Nrithya. 2020. “The Politics of Naming the South Indian Dancer.” Decolonizing

Dance Discourses: Conversations Across the Field of Dance Studies. XL. 13-15.

Prakash, Brahma. 2019. Cultural Labour: Conceptualising the "Folk Performance" in India.

New Delhi: Oxford University Press.

Ramanujam, Srinivasa. 2020. Renunciation and Untouchability in India: The Notional and the Empirical in the Caste Order. Abingdon: Routledge.

Santos, Boaventura de Sousa. 2018. The End of the Cognitive Empire: The Coming of Age of Epistemologies of the South. Durham: Duke University Press

Sarukkai, Sundar. 2009. "Phenomenology of Untouchability." Economic \& Political Weekly 44(37): 39-48.

Sarukkai, Sundar. 2019. Interviewed by the author via Skype. 20 September.

Soneji, Davesh. 2012. Unfinished Gestures: Devadasis, Memory, and Modernity in South India. Chicago: University of Chicago Press.

Subramanian, Ajantha. 2019. The Caste of Merit: Engineering Educating in India.

Cambridge: Harvard University Press

Tavag, Anishaa. 2020. Interviewed by the author via Zoom. 18 September.

Walsh, Catherine. 2018. "The Decolonial For: Resurgences, Shifts and Movements.” On

Decoloniality: Concepts, Analytics, Praxis, edited by Walter D. Mignolo, and Catherine E.

Walsh, 15-32. Durham: Duke University Press.

Yohalem, Hannah. 2018. "Displacing Vision: Contact Improvisation, Anarchy, and Empathy." Dance Research Journal 50(2): 45-61. 
1 'Unmaking' in this title is an implicit nod to the dismantling of dominant discourses in cultural anthropology that mobilize 'making contact' to often describe the first point of encounter between colonial forces and indigenous groups, between the Global North ethnographer and their Global South subjects of enquiry. 'Unmaking Contact' is about defining the parameters, experiences and prerogatives of such contact, both physical and metaphoric, on our own terms.

2 Three 'Touch Tales' are interspersed through this article and mobilize a more personal and reflective mode of writing to frame the intellectual, theoretical and analytical discussions in this essay. They function as interludes and as reminders of my own experiences that ground this study, navigating between the personal, the political, the philosophical, and the artistic dimensions of this article. In her doctoral thesis that examines selfies through the lens of performance studies, my graduate student Claire Hampton uses similar reflective interludes '\#Selfies' to offer glimpses into her personal relationships to selfies and self-portraitures. Positioned between chapters these interludes remind readers of what is at stake for her as a human being in this study. Hampton and I both use this methodological tool in our writings, through my 'Touch Tales' and her '\#Selfies', and while distinct in content, they offer similar spaces of reflections and ground the personal in the political.

${ }^{3}$ My book project Unmaking Contact: Choreographic South Asian Touch is contracted with Oxford University Press and my completed manuscript is due for submission in early 2023. 